$\$=$

\title{
Elderly abuse: Suffering in silence - who is listening? Some concern for social work practices
}

\author{
Avtar Singh $^{1} *$, Akshi Duggal ${ }^{2}$, Ravinder Singh $^{3}$, Upmesh K. Talwar $^{4}$ \\ ${ }^{I}$ Associate Professor \& Former Head, Department of Social Work, B.R. Ambedkar College, University of Delhi, Yahmuna Vihar, Delhi-94 \\ ${ }^{2}$ AssistantProfessor, Department of Social Work, Kurushestra University, Kurushestra, Haryana \\ ${ }^{3}$ Associate Professor \& Head, Department of Medical Anthropology, IHBAS Hospital, Faculty of Medical Sciences, University of Delhi, \\ Dilshad Garden, Delhi-95 \\ ${ }^{4}$ Social Worker(Psychiatry),Regional Institute for Mentally Handicapped, Sector-31, Chandigrah \\ *Corresponding author E-mail:avtar.singh@yahoo.com
}

\begin{abstract}
Paper highlights basic concepts of elder abuses and raises relevant issues concerning problems of elderly, which must be listened with utmost care. None of us claim convincingly that what is an extent of older person's problems and what is the appropriate solution. It is only possible through a caring unit of society, the family, if restructured on the values and reframing the sensitivity among kins $n$ kieth. Then elderly people may get a meaningful relationship among the family of genitor and extended family of procreator - younger children and their families. Otherwise their suffering, though how difficult or simple may, would continue as such, despite best economical resources, plans and programmes existing for them. Legal provisions to do exist to safeguard elderly people in family situations, but they are neither aware nor their progeny for caring them in extended families. Do we hear them or spend quality time as married sons or daughters, daughter in laws? Do our children spend time with grandfather? Or do we not leave them to alone with their suffering in silence? Overall in last, we do not have enough time to listen their problems-being alone, emotional disturbances, etc., and they remain to suffer in silences.
\end{abstract}

Keywords: Elderly; Abuses; Programs.

\section{Introduction}

Ageing is determinate patterns of late change after 40 years as one grows old in time and space. Physical Characteristics are gradual changes in appearances: greying, loss of hair and teeth, elongation of nose and ear, fat loss around the face, sagging skin, wrinkles, impairment of sensory functions such as visual, audition, smelling, tactility, feeling, etc. It also involves progressive structural changes that may result in shortened trunk with comparatively long arms and legs, and sickness increasing fragility accompanied by grimace and emotional negativism. Ageing is an inevitable and natural phenomenon all over the world. It starts from the embryo and continues until death. Precisely ageing brings changes in anatomical, physiological and psychological changes in life (Singhal, 1990; Neugarten, 1965). We are reviewing the situation of elderly people, their mains and general concerns, existing plan and programme and rapidly growing abuses to the elderly people in our country. Besides we also express our concerns to changing social work practices towards this population group.

The rate of diminishing capacities of physical work and sexual arousal become more prominent. These changes could be cumulated due to other ages related crisis like widowhood, marital problems, sexual problems, retirement, sensory loss susceptibility to disease, pains, hardiness of joints, loosening of muscles, physical inactivity, immobility, etc. (Chadha and Chao, 2006).The aged in any society poses crucial development tasks: the situations come from the combination of resources from their earlier lifestyle, from the availability of social, psychological and economical resources of the community and from the individual health and physical energies (Kennedy, 1978). Regardless of its diversified situation, the changes due to ageing process encompass all individuals, provided. They live long.

The number of elderly people worldwide will reach 1000 million. Europe would continue to be "oldest" region in the world with 25 per cent representation of a world elderly. Three-quarters of all deaths in developing countries could be ageing related. Out of 10 countries with largest population $60(+)$ will be from the Asian continent-Chine (230 million), India (142 million), Indonesia (29 million) and Pakistan (18 million).

In future condition of senior citizens is likely to worsen, with the ongoing rapid social and economic changes, it is expected to have serious implications on the circumstances under which the future elderly will live. These socio-economic changes comprise emergence of nuclear families, smaller number of children per couple, greater longevities, physical separation of parents from adult children as a result of rapid urbanization and age-selective rural-urban migration, together with the changing values of younger generations against the older ones(Ranjan, Mishra and Sharma, 1991).

\section{Situation of elderly people}

Elders in this context are persons of age 60 years and over. The Elderly population in 2001 was $7.08 \%$ i.e. 71697634 and in 2011 it was $8.18 \%$ i.e. 9786907 persons. Predictions indicate that by 2025 the global population of this age group will double to 1.2 
billion. One million people turn 60 every month and $80 \%$ of these are in the developing world.

Furthermore, the decadal percent increase in the elderly population for the period 2001-2011 is likely to be more than double the rate of an increase of the general population. The size of the elderly rose in absolute terms during the last century from 12 million in 1901 to approximately 71 million in 2001 and is likely to reach 113 million in 2016. However, another feature of ageing in India is the fact that the proportion of elderly is much higher in the rural areas than in the urban areas. The sex-wise pattern of growth of elderly population reveals that the increase is greater among women in the recent than the increase is greater among women in the recent past, which indicates that elderly women will outnumber elderly men in the future (Das and Shah, 2004).

One of the litmus tests for any welfare state is the kind of social security it provides for this vulnerable section. There has been a steady rise in the population of older persons in India. The number of elder persons increased from 19.8 million in 1951 to 76 million in 2001 , and the projections indicate that the number of $60+$ in India will increase to 100 million in 2013 and to 198 million in 2030. The life expectancy, which was around 29 years in 1947, has increased and now stands close to 63 years. The majority of (80 percent) of elderly population in India is in the rural areas, thus making service delivery to them a challenge, and there is a large number above 80-yearperson in the country (Pandya, 2013)

They have given life to us and we are not able to protect their lives. The increase in lifespan also results in chronic functional disabilities creating a need for assistance required by the older person to manage chores as simple as the activities of daily living. What are we doing? There is a growing realisation among older persons that they more often are perceived by their children as a burden. Now we enumerate some theoretical explanations.

\section{Theoretical explanations}

Desai and Raju (2000) have elaborated some of the theoretical explanations- social isolation, stress, intra-individual dynamics, impairment dependence, negative attitudes for elderly, and cycle of abuse of inter-generational transmission of violence about elder abuses which we summarized as follows.

Social isolation leads into lonely life and cannot interact with the other people of the society. This cloistered life pattern leads to increase their risk of being abused and research studies in this area support of this theory (Philips, 1993). Similarly, stress emphasizes interplay between intra-individual and social structural variables such as caregiver stress resulting from work or unemployment, life crisis, economic conditions, etc. When an elderly parent lives in a family and if all the members except children go out for work for the entire day which may arise in conflict, stress, misunderstanding, lack of discipline, disruption in communication; culminate in elderly abuse (Desai and Raju, 2000).

Intra-Individual dynamics also causes abuses sometimes possess a few personality traits, habits or some pathological characteristics, which make them abusive. This has been reiterated from time to time (Phillmer and Suitor, 1990) and has been under criticism (Gelles and Pedrick-Cornell, 1990). Sometimes dependence due to impairments leads to severe physical or mental impairments tends to become more dependents as well as more vulnerable to be abused. The basic reasons behind it that care-givers who are responsible to take care of these types of elderly people undergo tremendous physical and mental pressure, which make them impatient, a sense of irritation develops and which all get manifested in a form of abuse and neglect (Block and Sinnott, 1979).

A negative attitude towards elderly is another explanation. It may be that peoples' prevailing negative stereotype attitude towards the elderly and their roles in society. The conventional way of looking at the older people as somebody who is unproductive and useless human being and burden on the society. These negative attitudes tend to dehumanize old people and make it easier for an abuser to victimize them without feeling remorse (Giordano and Giordano,
1984). And the cycle of abuse of inter-generational transmission of violence reveals the abuse breeds abuse. It means that some point of time abuse in cyclical in nature. If a child gets abuse at his or her early age by the parents who sometimes manifests in a form of abuse by the children towards the parents. People learn to be violent when they grow up in violent homes. Such explanations may be viewed to pattern of their abuses.

\section{Pattern of elderly abuse}

The Pattern of elderly abuses may be broadly classified- physical abuse, mental abuse, sexual abuse; and emotional or psychological abuse, neglect; and abandonment, financial or material exploitation and self-neglect.

Physical abuse, which may be the use of physical force, which may result in bodily injury, pain or may leads to any impairment. It may include but is not limited to such acts of violence as striking (with or without) an object, hitting, beating, pushing, shoving shaking, slapping, kicking, pinching, and burning. In addition, inappropriate use of drugs and physical restraints, force-feeding, and physical punishment of any kind also are examples of physical abuse. Similarly mental abuse as the people grow older they develop worries, anxiety, depression, nervousness, persistent feeling of insecurity, some types of phobia such as loneliness, fear and helplessness, lack of confidence, loss of memory, incoherence in thought and ideas, psychological stresses, etc., as a result of which their creative participation in various affairs of society is hampered. There are three fears, which come with the old age viz. i. fear of dependence and uselessness. As a person ages, he begins to fear retirement, unemployment, financial insecurity, loss of mental keenness and mutual skill, and possibility to rely on children to support; ii. Fear of illness. As one gets older, fall in health often becomes a problem. An old person is no longer able to see or hear as he used to, his reflexes slow down, strength begins to add and such things an digestion and circulation grow sluggish; and iii. Fears of Isolation, the elderly develop the fear, that in case they are afflicted by any infectious disease, they may be isolated.

Sexual abuse is a non-consensual sexual contact of any kind with an elderly person or any contact with any person incapable of giving consent is also considered sexual abuse. It includes, but is not limited to, unwanted touching, all types of sexual assault or battery, such as rape, sodomy, coerced nudity, and sexually explicit photographing. Emotional or psychological abuse is an infliction of anguish, pain, or distress through verbal or nonverbal acts. It includes but is not limited to verbal assaults, insults, threats, intimidation, humiliation, and harassment. In addition treating an older person like an infant; isolating an elderly person from his/her or her family, friends, or regular activities; giving an older person the "silent treatment and enforced social isolation are examples of emotional/psychological abuse.

Neglect is another pattern of abuse which to refuse or failure to fulfil any part of a person's obligations or duties to an elder. It may also include failure of a person who has fiduciary responsibilities to provide care for an elder (e.g., pay for necessary home-care services) or the failure on the part of an in-home service provider to provide necessary care. It means the refusal or failure to provide an elderly person with such life necessities as food, water, clothing, shelter, personal hygiene, medicine, comfort, personal safety, and other essentials included in an implied or agreed-upon responsibility to an elder. Abandonment is a desertion of an elderly person by an individual who has assumed responsibility for providing care for an elder, or by a person with physical custody of an elder.

Financial or material exploitation is defined as the illegal or improper use of an elder's funds, property, or assets. Examples include, but are not limited to, cashing an elderly person's check without authorization or permission; forging an older person's signature; misusing or stealing an older person's money or possessions, coercing or deceiving an older person into signing any document (e.g., contracts or will); and the improper use of conservatorship, guardianship, or power of attorney. Self-neglect is behav- 
ior of an elderly person that threatensher or her own health or safety. It manifests itself in an older person as a refusal or failure to provide himself/herself with adequate food, water, clothing, shelter, personal hygiene, medication (when indicated), and safety precautions. It excludes a situation in which a mentally competent older person, who understands the consequences ofher or her decisions, makes a conscious and voluntary decision to engage in acts that threatenher or her health or safety as a matter of personal choice. The traditional norms and values of the Indian society laid stress on showing respect and providing care for the aged. However, in recent times, society is witnessing a gradual but definite withering of the joint family system, as a result of which a large number of parents are being neglected by their families exposing them to lack of emotional, physical and financial support. The older persons are facing a lot of problems in the absence of adequate social security. This clearly reveals that ageing has become a major social challenge and there is a need to provide for the economic and health needs of the elderly and to create a social milieu which is conducive and sensitive to emotional needs of the elderly. After knowing their pattern of their abuses, we are trying to develop some possible solution in metro cities: old-age homes are they really solution to their abuses? Let's see more about these homes asin following section.

\section{Old age homes}

What is more worrying? Though, it is the fact that old-age homes while remaining an alien idea in rural India, which have gained tremendous ground in main metropolitan cities of the country Since a large majority of older Indian live in rural areas, discussion of ageing in India is essentially s discussion of ageing in rural areas. There is a great influence of the western world in our society these days, and all of us have all together become very obsessed with materialistic things and money such that we are losing gradually our morality. So we should realize that we should take good care of the old people because everyone has to face this phase of life in the future. The old-age homes in Delhi are increasing day by day in number. No doubt it is of great help for the old and elderly people as they are being care in the old age homes by the society's concerned authorities, and they cater to all the needs of the old people very well. However, the major concern is the reason of increasing number of these old-age homes in India where there is a different traditional and cultural value all together as compared to other western countries.

\subsection{Care of the elderly in old age homes}

The decline of joint family system and risen of Nuclear or Singleparent family is an important factor that has undermined the position and status of the older adult (Jamuna, 2002; Bose, 2004). At the same time, modernization, technological advancement, mobility, changing lifestyle, and values, have altered the face of India The shortage of housing in cities, rising cost of living and dual career families hassled to the crunch of time, space and money. Further, evidence is changing priorities that effect of infra family distribution of income in favour of younger generation (Bose, 2004). All of these impacted the individual security in late life that was previously accorded to older adults in the context of the joint family and impacted intergenerational relationships.

\subsection{Old-age homes}

The concept of the old-age home, though not very common in India, is not unknown. The first old-age home was established in Bangalore in 1983 by the Bangalore Friends-in Need society. Oldage homes are the institution for the aged established either by the government, voluntary organization, Charitable Trust or Missionary Institutions for the welfare of the inmates, providing facilities for their stay. According to Help Age India estimates, there are 728 institutions at present, perhaps a majority of them in urban areas. Kerala has the largest number of old-age homes. More than 60 per cent of the old-age homes in India are of the charitable type, meant for destitute or very poor persons. About 20 per cent of them of the 'pay and stay' type and another 20 per cent are mixed. About 15 percent of the homes were for women exclusively. In recent years, there has been rapid increase in the number of old-age homes, and they are gradually gaining acceptance, especially by those see these institutions as a better alternative than living in a son's home where you are not wanted.

\subsection{The plight of elderly or suffering in silence - do we listen them?}

Aging means growing old without any indications about society aging or its complexities on account of persistent poverty growing diversities in older values and nuclear family, meeting the needs of the growing populations become the major concerns of the elderly population (Moneer, 2006). The elderly get affected due to lack of support from children who would have grown into adulthood and are in the web of fulfilling their own priorities. Many elders are quietly suffering indignity at the hands of those who they taught to say their first words and take their first steps. It is shocking that the largest perpetrators of Elder Abuse are their own children. When increasing number of younger generation started showing signs of selfish motives like acquiring the parents property and would show a mere trace of tolerance towards the parent that some of the independent parents with a sense of dignity and some economic resources decided it was time for them to move on in life. They felt insecure living with their children and instead started looking for the alternate living order, where their physical and emotional security would be ensured, and they would be able to lead a life of respect and dignity in the dusk years of their lives.

The fading joint family system in India and other innumerable factors have given rise to west-inspired phenomena of old-age homes. Surprising cost of living and scanty return on savings have almost pushed these senior citizens on roads. Old-age homes came out to fulfil the need of so many elder people. They did not want to be reminded by their children that they are a liability to them, and they could pay them by giving the children their properties.

The elderly citizens are in need of urgent attention. They do not need our pity, but the understanding love and care of the fellow human beings. It is our duty to see that they do not spend the twilight years of their lives in isolation, pain and misery. Due to social, economic, demographic changes as high fertility, increasing life expectancy, migration, and women are joining the labour force, intergenerational values changing in our society today. The remedies suggested by the respondents across different classes included self-adjustments, cooperation in resolving family conflicts, to expect less from the children, indulge in some productive work, better planning for one's own future within economic constraints, educating the children and to install in them cultural values right from the beginning, acting as a good role model for the origin of abuses the children. These changing attitudes are inevitably having severe psychological effects on the elderly and creating internal as well as external isolation resulting in them undergoing greater depression. Why do people abuse elderly? Who are these people?

\section{Factors instigating elder abuse}

During a discussion with participants in the seminar, it is shared that total dependency on the children increasing the problem, some said that they are over pressurize by the office work, taking care of the family members, feels frustrated, and as they are weak and show our anger on us. Some participants mentioned that there is no communication between them and their children. They feel them as burden and the least importance members in the family. They are no longer productive in any sense, especially male elderly family members. We enumerated some instigating factors as follows. 
- Isolation of victim

- Family greed

- Disability/medical reasons of the victim

- Seeking independence sought by the abuser, take them as overburden.

- Intergenerational conflict

- Retirement

- Lack of infrastructure facility

- Widowhood

- Dependency on the abuser

- Culture of violence

- Untrained and unresponsive attitudes of the elderly toward abusive situation.

Participants also developed some kind of understanding about abuse. They proposed some strategies to combat or to reduce the incidences of elder abuse in family situations.

i) Awareness and education: A common recommendation was to educate younger people to perceive the elderly as positive contributors to the family and society.

ii) Empowerment of elders.

iii) Role of media should help to create a positive image of elders in society.

iv) Recreational facility, and

v) Structural solutions.

\subsection{Who are the abusers?}

It has been estimated that roughly two-third of all elder abuse perpetrators are family members, most often the victim's adult child or spouse. Research reveals the abusers in many instances are financially dependent on the elder's resources and have problems related to alcohol and drugs. Daughters-in-laws became the threat for most of the mother-in-laws because of various reasons such as: personal dislikes, want property, want to live alone only with her husband and children, want in-laws not to interfere in their personal matter and so on. Family kins like son, daughter, daughter-in-laws, grandchildren, help providers, strangers, son inlaws, friends and relatives, etc. which are a list of abusers is increasing day by day and so their vulnerability.

We feel following may be the possible ways in which an elderly person can protect himself against abuse.

i) Make sure the financial and legal affairs are in order. If they aren't he must enlist professional help to get them in order, with the assistance of a trusted friend or relative if necessary.

ii) Avoid becoming isolated, which increases his vulnerability to elder abuse so keep in touch with family and friends.

iii) If one is unhappy with the care, he is receiving, whether it's in his own home or in a care facility, then he must speak up. $\mathrm{He}$ may tell someone he trusts and may ask for further help.

iv) If one is not in a position to help an elder, he can volunteer or donate money to help elderly. Moreover one can lobby to strengthen state laws and policing so that elder abuse can be investigated and prosecuted more readily. The life one saved down the line may be his own one day.

v) Parents are the most influential role-models in their children's lives. If a child witnesses his or her parent abusing an elderly family member, that child learns that acting aggressively towards elders is an acceptable behaviour.

vi) One should emphasize the need for families to express and manage their anger and frustration constructively, and model appropriate, non-aggressive behaviour for their children.

We now give a precisely our programmes and policies for elderly care, range of interventions and implication on the role of the social workers in next sections followed by the conclusion.

\section{Programmes and policies for elderly care}

Indian government has been committed, through its own constitutional provisions, to support the old people in our society with certain interventionist welfare methods since Independence. The
Article-41 of the Directive Principles of the State Policy states that the State shall protect the well-being of senior citizens. Apart from this, numbers of programmes and policies for elder person have been formulated as follows:

\subsection{The integrated programme for older persons (IPOP)}

IPOP programme is being implemented since 1992 with the objective of improving the quality of life of senior citizens by providing basic amenities. Such as food, shelter, medical care and entertainment, opportunities have been planned in their development programme. Besides they are encouraged for productive and active ageing through support for capacity building of Government/Nongovernmental organization organisation (GOs/NGOs), Panchayati Raj Institutions, Local bodies in the community. The scheme has been made flexible to meet the diverse needs of older persons, including reinforcement and strengthening of the family, awareness generation on issues pertaining to older persons, popularization of the concept of lifelong preparation for old age, facilitating productive ageing, etc. It was revised in April 2008. The amount of financial assistance for existing projects, some more projects has been added as being eligible for assistance under the IPOP Scheme.

\subsection{National social assistance programme (NSAP)}

NSAP was launched on August 15, 1995. The aim of this programme was to provide social assistance benefit to the elderly poor in rural areas, death of primary bread earner and for poor women during maternity. It aims at providing them a sense of dignity and support thereby ensuring a minimum quality of care and attention from the community. It has provided an opportunity for linking the social assistance package to schemes for poverty alleviation and provision of basic needs. It is a Centrallysponsored scheme with 100 percent central assistance provided to States/UTs. This programme is implemented through partnership with State Governments and under the direct supervision of District Rural Development Agencies (DRDAs) in close collaboration with the various Panchayat Raj Institutions (PRIs). The NSAP comprises of five schemes: i. India Gandhi National Old-Age Pension Scheme (IGNOAPs); ii. India Gandhi National Widow Pension Scheme (IGNWPS); iii. India Gandhi National Disability Pension Scheme (IGNDPS); iv. National Family Benefit Scheme (NFBS), and v. Annupurna.

\subsection{The national policy for older persons (1999)}

The Government announced the National Policy on Older Persons (NPOP) in 1999 was in response to the increasing number and proportion of older persons and their disadvantaged status in terms of general social, economic and physical well-being. The demographic transition process has been accompanied by industrialization, urbanization, migration and modernization, resulting in changing values and lifestyles, which contest the traditional values regarding accommodation of the elderly within households (GOI, 1999).

The policy provides a broad framework for inter-sectoral collaboration and cooperation both within the government as well as between governmental and non-governmental agencies. The Policy highlights the holistic approach toward older persons is sustained in the policy by identifying priorities such as social assistance and security, health, shelter, education, freedom from abuse and exploitation, research, training and Manpower, besides several others. The challenge of implementing such a multi-level and multi-dimensional mandate is enormous. It calls for coordination, leadership, effective strategic, networking, lobbying and advocacy. Above all, it calls for effective monitoring, feedback and continuous system improvement. The institutional mechanisms that are in place or are being set up to oversee the policy implementation are therefore, of crucial significance. The policy has identified a number of areas for intervention i.e. financial security, health 
care and nutrition, shelter, education, research, welfare, protection of life and property of media (GOI, 1999).

\section{Range of interventions}

There are a range of interventions, and people have the right to know all the options that are available to them. These may include introducing support of counselling services, arranging respite care, separating the victim from the abusive situation, finding alternative accommodation or taking legal action.

i) Crisis Care: This might involve admission to an acute hospital bed, or perhaps urgent respite care in a nursing home or hostel, depending on the needs of the victim. In cases of severe physical abuse, the victim often needs to be immediately separated from the abuser, and necessary legal action is needed to be taken against the abuser.

ii) Provision of community supports services: the full range of community support services such as home nursing, housekeeping help, Community options and meals on wheels can be used to alleviate situations where abuse is occurring. Assistance with shopping and transport is of practical help to the career. Fighting for the rights of the people is not an individual task; it is a hand holding process of the family, friend, relatives and neighbours.

iii) Elder Abuse Prevention Units Help line. Age-well Foundation and Help Age India can perform their role in preventing elder from abuse.

iv) Provision of respite care: This may be in-home respite, daycentre respite, or residential respite. This is particularly helpful when carer stress is an issue and where there has been a situation of neglect. If the victim is quite dependent, then often nursing-home respite care is the only alternative.

v) Counselling: This may involve individual and family counseling. It also includes family therapy. The aim is to help victims cope with their situation, and assist the victim to find a way to be safe from their abusers. In some cases where domestic violence is the main cause of abuse, a referral may need to be made for appropriate services for victims of domestic violence. Counsellors should have appropriate expertise.

vi) Legal Intervention: These are hopefully a last resort, but may be the first line of intervention where criminal charges need to be laid in cases of financial abuse or server physical abuse. People who are competent to make their own decisions can, with support if necessary, access mainstream legal services (GOI, 1999).

\section{Implication and Role of social workers}

There are main concerns for social workers while dealing with elderly in geriatric setting are which are summarized as follows.

i) We have category of the people who are not abused by anyone, especially by their own family members. We can develop a support group of these elder groups, who can guide and protect those victims who are abusing by their family members and with those who have been severely abused and taken help of some Governmental, Non-Governmental Organisation and law and order.

ii) Sensitizing community can be an important strategy to mitigate the incidence of elder abuse.

iii) Identify and respond to the barriers to identify the factors instigating abuse and take action for them.

iv) Training of professional in counselling to the targets group.

v) Provided assistance to fight for their rights.

vi) Involved media in assistance and creating a positive image in front of society.

vii) Conduct more research and disseminate research findings.

viii) To develop the strategies to prevent and intervene specially older people living within the family fold and subjected or facing abuse. ix) It is very important to make placements of social work students in Old-Age Homes, in schools and colleges to sensitize the community so that such problems related to elderly could be controlled.

\section{Conclusion}

We will all grow old one day-if we have those privileges. Therefore, look at older persons not as people separate from our-selves, but as our future selves. And let us recognize that people are all individuals, with individual needs and strengths, not groups that are all the same because of their age. To conclude it can be said that the problem of elderly must be addressed with utmost care. However, it is also a fact that the nation cannot afford to arrange total institutionalization for the growing population of elderly. Old-age Home cannot be the solutions. It requires huge investment in term of men, money, and materials. Precisely no one can claim, nor do we do, convincingly that what extent the older person's problem may be solved. It is only possible that the caring unit of society, the family, if restructured on the values and reframing the sensitivity among kins $n$ kieth. Then elderly people may get a meaningful relationship among the family of genitor and family of procreator - younger children and their families. Otherwise their suffering, though how difficult or simple may, would continue as such, despite best economical resources, plans and programms existing for them. Legal provisions do exist to safeguard the elderly people in family situations, but neither are they aware nor their progeny for care in extended families. Overall in last, we do not have enough time to listen their problems-being alone, emotional disturbances, etc., and they remain to suffer in silences. Do we hear them or spend quality time as married sons or daughters, daughter in laws? Or do not we leave them to alone with their suffering in silence?

\section{Acknowledgement}

(We are highly debited to the comments of the delegates of International Conference on Ageing through the Ages: from Past to Present and Future organised by Department of Sociology, R.T.M Nagpur University, and Nagpur 5-6 December, 2014. Their suggestions have been incorporated in the paper. We are also thankful to our colleagues in the Department of Social Work who had seen its earlier drafts and made their critical comments. We extends warm gratitude to the Editor, IJH and the positive reports of the three anonymous reviewers)

Note: This is the revised Paper after International Conference on Ageing through the Ages: from Past to Present and Future organised by Department of Sociology, R.T.M Nagpur University, and Nagpur 5-6 December, 2014

\section{References}

[1] Block, E. and Sinnott, J. (1979). The Battered Elders Syndrome, College Park, MD: Centre on Ageing, Unpublished manuscript.

[2] Bose, A. (2004). Growing Old in India-Voice Reveal Statistics speak, B.R. Publishing Corporation, New Delhi.

[3] Chadda, N.K. (2004). Building Society through Intergenerational Exchange. Indian Journal of Gerontology, Volume 18, No. 2 pp. 227 236.

[4] Chadda, N. K..and Chao, D. (2006). Marital status and leisure activities among the elderly. Research and Development Journal. Vol. 10 No.3 October 2006. 8-13

[5] Desai, M. and Raju, S. (2000). Gerentological Social Work in IndiaIssues and Perspectives. B.R. Publishing Corporation, Delhi.

[6] Das, N, P. and Shah, U. (2004). A Study of Old Age Homes in the care of the Elderly in Gujarat. A special report prepared as a part of the research initiative at the Population Research Centre, Baroda for the MOHFW, New Delhi.

[7] Gelles, R. and Pedrick-Cornell, C. (1990).Intimate violence in Families $\left(2^{\text {nd }}\right.$ Ed), New Delhi: Sage. 
[8] Giordano, N. and Giordano: (1984). Elder abuse - A Review of the Literature, Social Work, 29 (3) 232-236.

[9] GOI (1999). The National Policy on Older Persons, Ministry of Social Justice and Empowerment, Shastri Bhawan, Government of India(GOI), New Delhi.

[10]Jamuna, D. (2002). Care giving Issues and Elderly Abuse in India Institutional Journal of Aging Policy and Research, Vol 15 (2/3), 1130 .

[11]Kennedy, C.E. (1978). Human Development: The Adult Year and Aging, New York, Macmillan Publishing Corporation.

[12]Moneer, A. (2006). Aging in India, socio-economic and health dimension, Academic Foundation, New Delhi.

[13]Neugarten, B.L. (1965) cited in Jones, R. (1975). The Older Generation: The new power of older people, New York, Prentice Hall.

[14]Phillips, I. (1993).The Dangers of Dependency: New Findings on Domestic Violence against the Elderly, Social Problems, 33, 146-158.

[15]Pillemer, K and Suitor. (1990). Personnel to Serve the Aging in the Field of Social Work: Implications for Educating Professionals, Social Work, 35 (5), 412-415.

[16]Pillamer, K.A and Suitor.J.J. (1988). Elder abuse. In V. Hassett, R. Morrison, A Belack and M. Hansen (Eds), Hand book of family violence. New Delhi: Plenum Press, 247-270 http://dx.doi.org/10.1007/978-1-4757-5360-8 11.

[17]Payne, B.K. (2005). Crime and Elder Abuse: An Integrated Perspective, $2^{\text {nd }}$, edition, Charles C. Thomas Publisher, Springfield, USA.

[18]Pehlan, A. (2013). International perspective on Elder Abuse,Advances in Health and Social Policy, Routledge, New York.

[19]Pandya, R (2013). Social Justice and Empowerment of Disadvantaged Groups in India Policies and Programmes, New Century Publications, New Delhi

[20]Rajan, S., Mishra, U.S, and Sharma. Iruday. (1999). India's Elderly Burden or Challenges Sage Publishing India Pvt. Ltd. New Delhi.

[21] Singhal, (1990), Human Aging: Some psychological perspective. In R.C. Singh and G.S. Sighal (Eds), Perspective in Aging Research, Houston, Scholarly Publication. 